This item is the archived peer-reviewed author-version of:

\title{
Microwave-assisted synthesis of mesoporous titania with increased crystallinity, specific surface area, and photocatalytic activity
}

\section{Reference:}

Meire Mieke, Verbruggen Sammy, Lenaerts Silvia, Lommens Petra, Van Der Voort Pascal, Van Driessche Isabel.- Microwaveassisted synthesis of mesoporous titania with increased crystallinity, specific surface area, and photocatalytic activity Journal of materials science - ISSN 0022-2461 - 51:21(2016), p. 9822-9829

Full text (Publisher's DOI): http://dx.doi.org/doi:10.1007/S10853-016-0215-Y

To cite this reference: http://hdl.handle.net/10067/1400980151162165141 
Received: 20 May 2016

Accepted: 11 July 2016

(C) Springer Science+Business Media New York 2016

\title{
Microwave-assisted synthesis of mesoporous titania with increased crystallinity, specific surface area, and photocatalytic activity
}

\author{
Mieke Meire ${ }^{1}$, Sammy W. Verbruggen ${ }^{2}$, Silvia Lenaerts ${ }^{2}$, Petra Lommens ${ }^{1}$, Pascal Van Der Voort ${ }^{1}$, \\ and Isabel Van Driessch ${ }^{1, *}$ \\ ${ }^{1}$ Department of Inorganic and Physical Chemistry, Sol-gel Centre for Research on Inorganic Powders and Thin films Synthesis \\ (SCRiPTS), Ghent University, Krijgslaan 281 (S3), 9000 Ghent, Belgium \\ ${ }^{2}$ Department of Bioscience Engineering, University of Antwerp, Groenenborgerlaan 171, 2020 Antwerp, Belgium
}

\begin{abstract}
Mesoporous titanium dioxide is a material finding its use in a wide range of applications. For many of these, it is important to achieve a high degree of crystallinity in the material. It is generally accepted that the use of the soft templating approach to synthesize mesoporous titania, results in a compromise between crystallinity and specific surface area due to thermal instability of the used templates. In this paper, we explore how the use of microwave irradiation $\mathbf{A Q 1}$ can influence the crystallinity, specific surface area, and the electronic properties of mesoporous titania. Therefore, we combined microwave radiation with an evaporation-induced self-assembly (EISA) synthesis. We show that additional microwave treatment at carefully chosen synthesis steps can enhance the crystallinity with $20 \%$ without causing significant loss of surface area $\left(>360 \mathrm{~m}^{2} / \mathrm{g}\right)$. Surface photovoltage measurements were used to investigate the electronic properties. The photocatalytic activity of the samples was evaluated in aqueous media by following the degradation of an industrial dye, methylene blue, and the herbicide isoproturon under UV irradiation and in gaseous media looking at the degradation of acetaldehyde, a common indoor pollutant under UVA irradiation. In all cases, the microwave treatment results in more active materials.
\end{abstract}

\section{Introduction}

Titanium dioxide is a widely used material as it is cheap, nontoxic, and thermally and chemically stable under a wide range of conditions [1]. It has various applications like pigment in paint and absorber in sunscreen, in gas sensors [2] or as catalyst support [3]. The most wellknown application, however, is its use as photocatalyst for the degradation of organic pollution in air or water $[4,5]$, the deactivation of bacteria [6], and the generation of $\mathrm{H}_{2}$ through the means of water splitting [7].

Address correspondence to E-mail: Isabel.VanDriessche@UGent.be

DOI 10.1007/s10853-016-0215-y

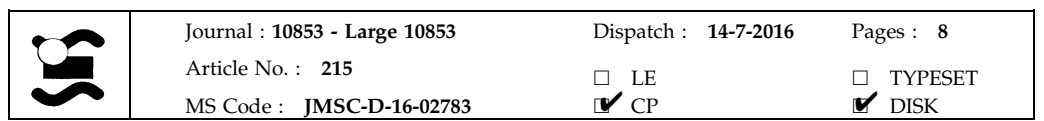


Many of these applications rely on surface-related phenomena and therefore, increasing the specific surface area of titania can significantly enhance its performance as a (photo)catalyst or gas sensing material. High specific surface areas can be achieved by inducing pores into the material. Most synthesis approaches are based on the concept of templating: a hard (silica, carbon) or soft (surfactants, biomolecules) template is introduced during synthesis of bulk titania and removed afterward creating a controlled morphology including pores of selected dimensions and in some cases an ordered pore structure [8-13]. In this work, we focus on the soft templating approach, in which an organic template molecule forms micelles and liquid crystals in solution around which the $\mathrm{Ti}^{4+}$-precursor can hydrolyze and condense. This approach offers a cheap, simple, scalable synthesis with one important drawback: due to the thermal instability of the organic templates there is a compromise between the crystallinity and the specific surface area of the materials as the need of crystallization at higher temperatures results in pore collapsing [12-17].

However, for many of the applications of titania listed above, the crystallinity of the material also plays an important role. In the use of titania as photocatalyst, the crystal composition has a strong influence on the charge recombination rate and therefore also on the photocatalytic activity itself [18].

Therefore, we have explored if the crystallinity of mesoporous titania obtained from soft templating can be enhanced by introducing microwave irradiation during selected synthesis steps. In case of titania nanoparticles synthesized through hydrothermal methods, it has been shown earlier that microwave irradiation improves the crystallinity of the nanoparticles and allows reducing synthesis temperature and time [19-22]. A few articles discuss the synthesis of mesoporous titania with microwave irradiation, but the amount of amorphous material in the samples is not quantified and no comparisons are made with conventional methods [23-25].

In this work, we have selected an established literature-based soft templating method: evaporationinduced self-assembly (EISA) synthesis using cetyltrimethylammonium bromide as soft template $[13,15,16,26-28]$. This method results in a mesoporous titania powder with a high specific surface area $\left(>300 \mathrm{~m}^{2} \mathrm{~g}^{-1}\right)$. XRD analysis combined with quantitative Rietveld refinement shows that the use of microwave irradiation during the synthesis enhances the crystal fraction of mesoporous titania without causing important losses in specific surface area. The photocatalytic activity of the resulting powders was tested for both aqueous and gaseous systems. Methylene blue, a common dye in the textile industry and isoproturon, a persistent herbicide were used as test molecules for the photocatalytic activity in aqueous media. In the case of the air purification application, acetaldehyde, a common pollutant indoors, was the test molecule. In both cases, the additional microwave treatment and consequential increased crystallinity also resulted in the increased photocatalytic activity of the titania powders.

\section{Experimental}

\section{Chemicals}

Titanium(IV) isopropoxide $\left(\mathrm{Ti}\left(\mathrm{O}^{\mathrm{i}} \mathrm{Pr}\right)_{4}, \geq 97 \%\right)$, methylene blue hydrate $(\geq 95 \%)$, and isoproturon (PESTANAL ${ }^{\circledR}$, analytical standard) are purchased from Sigma-Aldrich; hexadecyltrimethylammonium bromide (CTAB, $\geq 98.0 \%)$ is acquired from TCI, and ethanol (absolute PA) from Panreac. All chemicals are used as received.

\section{Synthesis of titania powders}

We used the recipe described by Beyers et al. [26, 28]. A clear, colorless ethanolic solution $(6 \mathrm{~mL})$ containing $0.59 \mathrm{~g} \mathrm{CTAB}$ at $40{ }^{\circ} \mathrm{C}$ is mixed with a colorless solution of $5.7 \mathrm{~mL} \mathrm{EtOH}, 3 \mathrm{~mL} \mathrm{Ti}\left(\mathrm{O}^{\mathrm{i} P r}\right)_{4}$, and $1.2 \mathrm{~mL}$ $\mathrm{HCl}$. Distilled water $(2.06 \mathrm{~mL})$ is added drop wise while stirring vigorously. The resulting mixture is stirred for 15 min and transferred to a Petri Dish with a diameter of $9 \mathrm{~cm}$. This is kept in an oven at $75{ }^{\circ} \mathrm{C}$ for 3 days. The obtained yellow solid is subjected to a base treatment comprising $48 \mathrm{~h}$ refluxing in $50 \mathrm{~mL}$ 0.1 $\mathrm{M} \mathrm{NaOH}$ solution. The white powder is filtered, washed 3 times with distilled water, and dried overnight at ambient conditions. The calcination proceeds for $2 \mathrm{~h}$ at $450{ }^{\circ} \mathrm{C}$ with a heating rate of $2{ }^{\circ} \mathrm{C}$ $\min ^{-1}$. To investigate the influence of microwave irradiation on the crystallinity of the structure, an additional microwave treatment of $1 \mathrm{~h}$ at $120^{\circ} \mathrm{C}$ is performed at three different stages of the synthesis. In the first case, this is before the transfer to the Petri Dish and this sample is called MW 1, MW 2, and MW 3 underwent a microwave treatment, respectively,

$\begin{array}{lll}\text { Journal : } \mathbf{1 0 8 5 3} \text { - Large 10853 } & \text { Dispatch : } \mathbf{1 4 - 7 - 2 0 1 6} & \text { Pages : } 8 \\ \text { Article No. : } \mathbf{2 1 5} & \square \text { LE } & \square \text { TYPESET } \\ \text { MS Code : JMSC-D-16-02783 } & \checkmark \text { CP } & \checkmark \text { DISK }\end{array}$


Figure 1 Flow chart of the synthesis, with indications of the additional microwave irradiation steps.

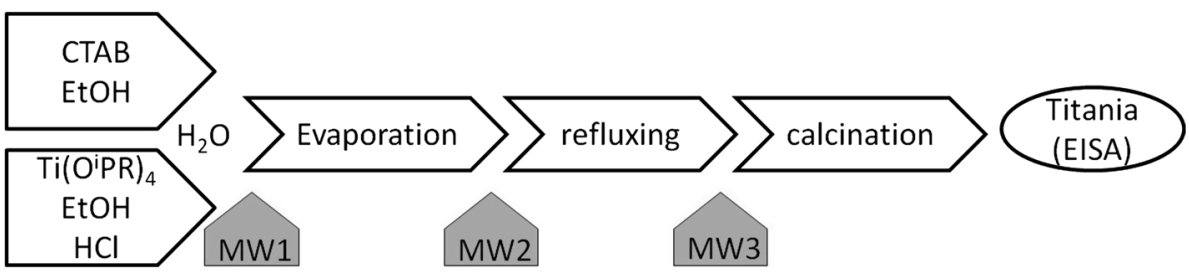

before and after the $\mathrm{NaOH}$ treatment. A flow chart of the synthesis is depicted in Fig. 1.

\section{Characterization}

Nitrogen sorption experiments are carried out on a TriStar 3000 (Micromeritics) at $-196{ }^{\circ} \mathrm{C}$. The specific surface areas are calculated using the Brunauer-Emmett-Teller (BET) method. X-ray diffraction (XRD) diffractograms are recorded on an ARL X'TRA Diffractometer (Thermo Scientific) equipped with a $\mathrm{Cu}-\mathrm{K} \alpha$ tube and a Peltier cooled lithium-drifted silicon solid state detector. To calculate the amorphous content of the samples, $10 \mathrm{wt} \% \mathrm{ZnO}$ is added as an internal standard [29]. The powders are side loaded onto the sample holder to reduce preferential orientation. The amorphous content is evaluated by quantitative Rietveld refinement using Topas Academic V4.1 software [30]. Total diffusion reflectance UV-Vis measurements on the titania powders are performed on a Varian Cary 500 spectrometer equipped with an integrating sphere coated with $\mathrm{BaSO}_{4}$. The reflectance is transformed to $F(R)$ using the Kubelka-Munk function. The indirect band gap is obtained from the $[F(R) \cdot E]^{2}$ versus the energy of the exiting light (E) plot by extrapolating the linear part of the graph, where the intersection with the $x$-axis represents the band gap energy. For TEM analysis, a copper support TEM grid (200 mesh) was dipped into an aqueous dispersion of the titania powders and air-dried. A JEOL JEM-2200FS transmission electron microscope with Cs corrector and an accelerating voltage of $200 \mathrm{kV}$ was used.

\section{Surface photovoltage (SPV) measurements}

The setup is a custom-made apparatus as described by Verbruggen et al. [31], in which the powder sample is sandwiched between two ITO electrodes (Sigma-Aldrich, $1.2 \mathrm{~mm}$ thickness, $8-12 \Omega \mathrm{cm}^{-2}$ resistivity), connected to an amplifier $\left(10^{6}\right.$ voltage amplification). No external bias is applied. In order to perform reproducible measurements, a section of $5 \mathrm{~mm} \times 5 \mathrm{~mm}$ is illuminated. $8.5 \pm 0.5 \mathrm{mg}$ of each catalyst is used to obtain a good contacting layer between both ITO electrodes. For the exact determination of the SPV value, the difference was taken between the voltage readout after $1.5 \mathrm{~min}$ of UVA illumination and the steady voltage readout in the dark. For all samples, four independent measurements were performed and averaged and the standard deviation was calculated to give an estimate of the error on the measurements.

\section{Photocatalytic degradation}

Water purification The photocatalytic activity of the powders is evaluated by following the degradation of methylene blue and isoproturon under UV illumination. The experiments are carried out in a setup based on ISO 10678:2010(E). A Vilber Lourmat VL315BLB blacklight blue fluorescent light tube is used with a maximum emission at $365 \mathrm{~nm}$ and emitting 10 $\mathrm{Wm}^{-2}$. The starting concentration of the aqueous methylene blue solution was 50 and $8 \mathrm{mg} \mathrm{L}^{-1}$ in the case of the isoproturon solution. Both experiments were conducted in the same way. $0.3 \mathrm{~g} \mathrm{~L}^{-1}$ titania was added to $50 \mathrm{~mL}$ pollutant solution in a photocatalytic cell which is kept at a constant temperature of $25{ }^{\circ} \mathrm{C}$. The suspension was stirred for $60 \mathrm{~min}$ in the dark to reach adsorption equilibrium. At frequent time intervals $2 \mathrm{~mL}$ dispersion was centrifuged for $5 \mathrm{~min}$ at $5000 \mathrm{rpm}$ to separate the titania powder from the pollutant solution. The pollutant concentration was evaluated using a Shimadzu UV1800 UV spectrometer at $665 \mathrm{~nm}$ in the case of methylene blue and $245 \mathrm{~nm}$ in the case of isoproturon. The degradation is normalized with respect to the starting concentration after reaching adsorption equilibrium.

Air purification All samples $(20 \mathrm{mg}$ ) were first suspended in $1 \mathrm{~g}$ absolute ethanol and stirred ultrasonically. For each sample, two precleaned glass slides $\left(2.5 \times 1.5 \mathrm{~cm}^{2}\right)$ were drop casted with $300 \mu \mathrm{L}$ of its

\begin{tabular}{|c|c|}
\hline Dispatch : 14-7-2016 & Pages: 8 \\
\hline $\begin{array}{l}\square \text { LE } \\
\sim \mathcal{C P}\end{array}$ & $\begin{array}{l}\square \text { TYPESET } \\
\boldsymbol{~ D I S K ~}\end{array}$ \\
\hline
\end{tabular}


suspension. The slides were left to dry to the air and were then transferred to an oven at $100{ }^{\circ} \mathrm{C}$ for further drying overnight.

Acetaldehyde was used as model pollutant. A polluted gas flow was generated by premixing $1 \%$ acetaldehyde in $\mathrm{N}_{2}$ (Praxair) with synthetic air (Praxair), resulting in an acetaldehyde concentration of $30 \pm 3$ ppmv. The samples were placed in the center of a single pass, slit-shaped flatbed photoreactor. A Philips Cleo UVA tube $\left(\lambda_{\max }\right.$ of $365 \mathrm{~nm}$, incident intensity of $3 \mathrm{~mW} \mathrm{~cm}^{-2}$ at sample distance) was used as light source. The test procedure is similar as described in earlier work [32-34]. Briefly, the measurements were carried out in several phases: (1) the dark reactor is flushed with clean air. (2) The reactor is illuminated and flushed with clean air. During this step, adsorbed rest fractions of solvents form the synthesis of coating protocols are photocatalytically removed from the substrate. (3) The pollutant reference level is measured by flowing polluted air directly to the detector, not passing the reactor. (4) Polluted air is passed through the dark reactor to determine the adsorption of the pollutant. (5) The reactor is illuminated and the photocatalytic activity is monitored. The concentrations of acetaldehyde and $\mathrm{CO}_{2}$ are monitored online by FTIR spectroscopy. The FTIR absorbance is converted into an actual concentration using preestablished calibration curves constructed using an organic vapor sensor and $\mathrm{CO}_{2}$ sensor. For each sample, an automated test protocol is run, that goes through the test phases described above three consecutive times, with 15 min polluted flow through the reactor in dark and $20 \mathrm{~min}$ under UV illumination. The standard deviations are calculated to give an estimation of the error on the measurements.

\section{Results and discussion}

\section{Specific surface area and crystallinity}

Table 1 shows quantitative information on the fractions of the crystal phases present in the different samples. The EISA sample is the least crystalline, with $35 \mathrm{wt} \%$ anatase. We performed a microwave treatment at different stages of the synthesis to enhance the crystallinity of the material. For all three samples, the anatase phase increased with at least $15 \%$. MW 1 exhibits a large fraction of $24 \%$ brookite, next to an increased anatase fraction of $57 \%$. The microwave procedure for the MW 1 sample is performed on the ethanolic precursor solution, which results in higher pressures in the reaction vessels than with aqueous solutions. As brookite is generally formed at higher pressures, it explains why the brookite phase is only observed in this sample. MW 2 has the highest anatase fraction of $82 \%$, but also the anatase content of MW 3 increased to $50 \%$.

The specific surface areas of the mesoporous titania samples obtained from BET analysis are also listed in Table 1. The untreated EISA sample exhibits a specific surface area of $318 \mathrm{~m}^{2} \mathrm{~g}^{-1}$. In most of the samples, the microwave treatment did not result in a large loss in specific surface area, except for MW 2, where a decrease to $202 \mathrm{~m}^{2} \mathrm{~g}^{-1}$ is observed. The preservation of the specific surface area of MW 1 during the microwave treatment can be explained by the hydrolysis behavior of the titania precursor, preferentially leading to nanoparticles [35]. This means that during microwave synthesis, particle formation is further enhanced, leading to increased crystallinity but leaving the specific surface area mainly unchanged. In the case of MW 2 and MW 3, the microwave treatment is performed after
262

263

264

265

266

267

268

269

270

271

272

273

274

275

276

277

278

279

280

281

282

283

284

285

286

287

288

289

290

291

292

293

294
Table 1 Crystal fractions, specific surface areas, and band gap energies of the titania samples

\begin{tabular}{llclll}
\hline & ${\text { Anatase }(\%)^{\mathrm{a}}}^{\mathrm{a}}$ & ${\text { Brookite }(\%)^{\mathrm{a}}}$ & ${\text { Other }(\%)^{\mathrm{b}}}$ & $\mathrm{S}_{\text {BET }}\left(\mathrm{m}^{2} \mathrm{~g}^{-1}\right)$ & Band gap $^{\mathrm{d}}(\mathrm{eV})$ \\
\hline EISA & 35 & 0 & 65 & 318 & 3.49 \\
MW 1 $^{\mathrm{c}}$ & 57 & 24 & 19 & 267 & 3.49 \\
MW 2 $^{\mathrm{c}}$ & 82 & 0 & 18 & 202 & 3.47 \\
MW 3 $^{\mathrm{c}}$ & 50 & 0 & 50 & 361 & 3.41 \\
\hline
\end{tabular}

${ }^{a}$ When a crystal phase fraction of less than $1 \%$ is found, this is neglected

b 'Other' includes amorphous fractions, undetermined crystalline phases, and adsorbed molecules

c The microwave treatment of MW 1 is performed before its transfer to a Petri Dish. In case of MW 2 and MW 3, the microwave treatment is performed, respectively, before and after the $\mathrm{NaOH}$ treatment

$d$ The band gap energy is calculated from the $[F(R) \cdot E]^{2}$ versus the energy (E) plot (Fig. S1)

\begin{tabular}{|llll|}
\hline Journal : 10853 - Large 10853 & Dispatch : 14-7-2016 & Pages : 8 \\
& Article No. : 215 & $\square$ LE & $\square$ TYPESET \\
MS Code : JMSC-D-16-02783 & $\checkmark$ CP & $\square$ DISK \\
\hline
\end{tabular}


assembling the titania particles around the template by evaporating the solvent. For MW 2, the microwave treatment is done before the refluxing step with $\mathrm{NaOH}$, leading to a collapse of the pore structure while in MW 3, including microwave treatment after refluxing with $\mathrm{NaOH}$, the pore structure is maintained or even enhanced. Beyers et al. [28], have shown that a $\mathrm{NaOH}$ treatment after EISA and prior to calcination at elevated temperatures, stabilizes the porous structure by crystallization of the walls of the mesoporous titania. This explains why the structure does not collapse when the microwave treatment is performed after the $\mathrm{NaOH}$ treatment (MW 3), but does collapse when it is performed prior to this treatment (MW 2). TEM analysis of the samples (Fig. S2) shows that all samples have the same morphology namely an agglomeration of small $(\sim 6 \mathrm{~nm})$ titania crystallites, forming large particles of $100-200 \mathrm{~nm}$. MW 2 is more dense, but the crystallites are of the same size as the other samples.

Total reflectance UV-Vis measurements are per22 formed to calculate the band gap energies (Table 1). The titania powders have a band gap of approximately $3.5 \mathrm{eV}$, except for MW 3, which has a smaller band gap of $3.41 \mathrm{eV}$. Due to this smaller band gap, a larger part of the UV-Vis spectrum will be absorbed. The band gap energies are somewhat higher than the $3.2 \mathrm{eV}$ reported for bulk titania, but normal for materials consisting of nanosized crystallites [1].

\section{Electronic properties}

Surface photovoltage (SPV) measurements give a qualitative image of the formation capacity and stability of photogenerated charge carriers for the samples (Fig. 2). All microwave-treated samples have an increased SPV signal compared to the nontreated (EISA) sample, which is in line with an increased degree of crystallinity. The increase in SPV signal is, however, not proportional to the crystallinity. Especially in the case of MW 2, the increase in SPV signal is rather small in comparison to the immense increase in crystallinity. Its specific surface area has, however, decreased significantly, making it more difficult for the photogenerated charge carriers to reach the surface, resulting in a small increase in SPV signal. The SPV signal of MW 3 on the other hand is larger than expected when solely looking at the degree of crystallinity as the crystallinity increase is smaller for MW 3 than for MW 1. However, taking into account the

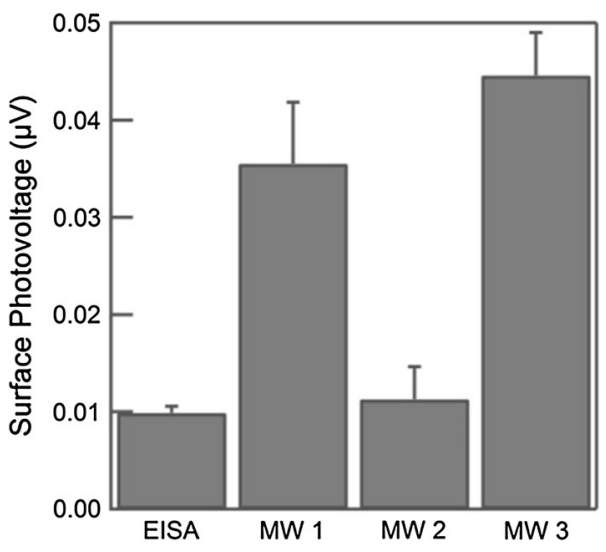

Figure 2 Surface photovoltage signals under UVA illumination. The error bars represent the standard deviation on the measurements.

increase in specific surface area for MW 3 and the small decrease for MW 1, and the somewhat smaller band gap of MW 3, the resulting SPV signals can be explained.

\section{Photocatalysis}

A first evaluation of the photocatalytic activity of the samples in aqueous media was performed by following the degradation of methylene blue as a test molecule for organic pollutants. We switched on the UV-lamps after the adsorption step described above. At regular time intervals, an aliquot is taken from the reactor and analyzed by UV-Vis spectroscopy. The resulting graphs are depicted in Fig. 3a. MW1 is a bit less active than the untreated titania material even though it has an increased crystalline fraction and a higher SPV signal. However, its specific surface area is lower than the untreated sample. MW 2 is even less active as its specific surface area is even lower and its SPV signal is much lower than MW1. MW3 on the other hand has a higher anatase fraction, leading to a high surface photovoltage, a higher specific surface area, and a smaller band gap resulting in an increased photocatalytic activity. The two most active samples were also tested for the photocatalytic degradation of a persistent herbicide, isoproturon (Fig. 3b). Also in this application, the microwavetreated sample, MW 3, was the most active.

The photocatalytic activity in air was investigated by the degradation of acetaldehyde. The activity is represented in terms of the steady state $\mathrm{CO}_{2}$ levels (with $\mathrm{CO}_{2}$ the final degradation product) generated during UV illumination at a total flow rate of $400 \mathrm{~cm}^{3}$

$\begin{array}{lll}\text { Journal : } \mathbf{1 0 8 5 3} \text { - Large 10853 } & \text { Dispatch : 14-7-2016 } & \text { Pages : } \mathbf{8} \\ \text { Article No. : } \mathbf{2 1 5} & \square \text { LE } & \square \text { TYPESET } \\ \text { MS Code : JMSC-D-16-02783 } & \mho_{\text {CP }} & \checkmark \text { DISK }\end{array}$


(a)
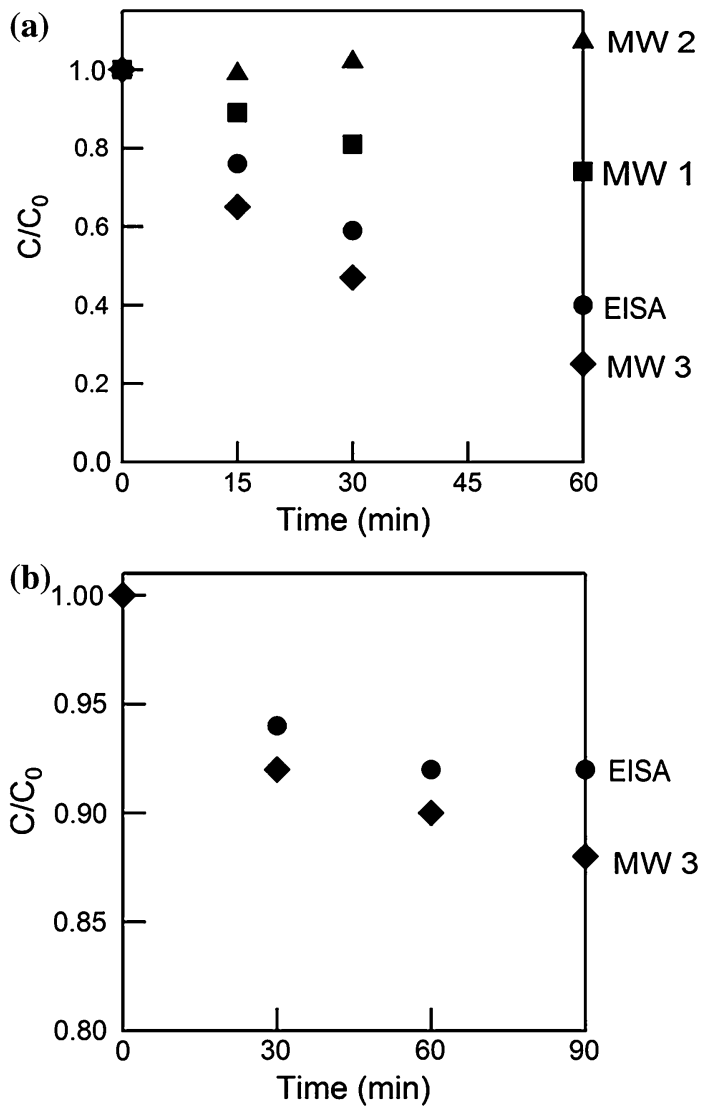

Figure 3 Photocatalytic degradation of aqueous a methylene blue and $\mathbf{b}$ isoproturon solutions as a function of time.

$\mathrm{min}^{-1}$ and an acetaldehyde inlet concentration of $30 \pm 3$ ppmv (Fig. 4). All microwave-treated samples are more active than the untreated sample, but MW 1 clearly shows the highest improvement.

In general, there is a good agreement between the amount of $\mathrm{CO}_{2}$ produced during the photocatalytic degradation of acetaldehyde and the SPV signal of the corresponding samples. Compared to EISA, the observed trends for MW 1 and MW 2 are almost identical, although the SPV signal for MW 3 appears illogical.

To compare the samples with regard to their intrinsic electronic properties, the photocatalytic activities are represented per unit of area. When this is compared to the anatase fractions in the samples, a very good agreement can be observed (Fig. 5). In the case of gaseous photocatalytic degradation of acetaldehyde, the higher the anatase fraction in the sample, the more active the sample is in terms of activity per unit of area, here the most active sample is MW 2. In the case of the absolute activity of the samples, the specific surface area has to be taken into

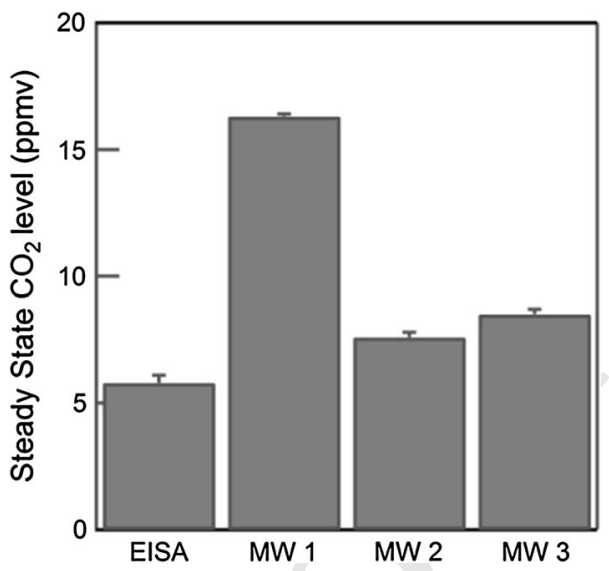

Figure 4 Photocatalytic steady state $\mathrm{CO}_{2}$ formation during acetaldehyde degradation under UVA illumination. The error bars represent the standard deviation on the measurements.

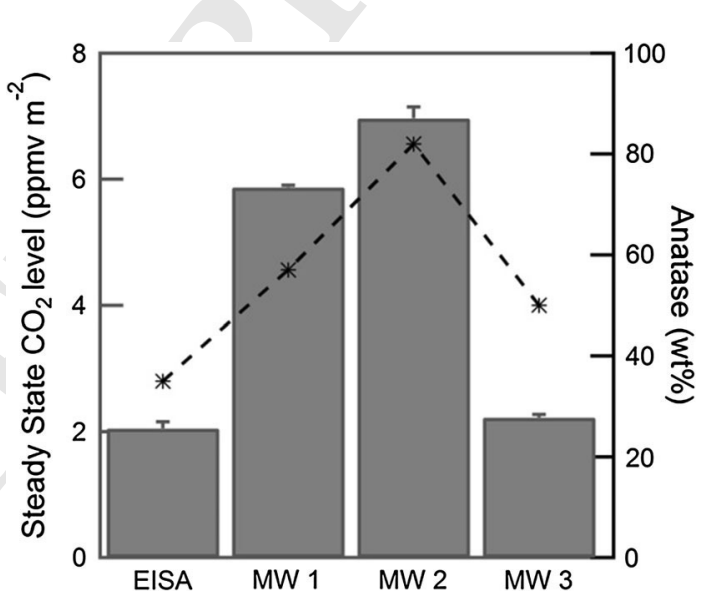

Figure 5 Area-based photocatalytic activity during acetaldehyde degradation (left) and anatase fractions (right) of the samples. The error bars represent the standard deviation on the measurements.

account, which is lowest for MW 2 compared to EISA, resulting in MW 1 being the most active sample overall.

It should be noted that the relative activity of the samples is different for the aqueous-phase and gasphase degradation reactions. Photocatalysis is a complex process that relies on an interplay of many parameters, not only of the catalyst but also the reaction conditions (irradiation intensity, reactor geometry, concentration, flow rate, etc.) have an important influence. It is therefore reasonable to assume that incorporating the microwave treatment at different times of the synthesis will induce different additional variations in the catalyst properties that render them more (or less) suited for applications under a given set of reaction conditions. It is

\begin{tabular}{|l|lll|}
\hline Journal : 10853 - Large 10853 & Dispatch : 14-7-2016 & Pages : 8 \\
& Article No. : 215 & $\square$ LE & $\square$ TYPESET \\
MS Code : JMSC-D-16-02783 & $\sim$ CP & DISK \\
\hline
\end{tabular}


413 clear though, that these microwave treatments 414 improve the crystallinity of the samples without 415 greatly compromising the active surface area. As a 416 result, the added value of the microwave treatment is 417 also apparent from all conducted photocatalytic 418 experiments under very divergent conditions, even 419 though the order of reactivity is different.

\section{Conclusions}

Mesoporous titania was synthesized according to an evaporation-induced self-assembly synthesis. To enhance the crystallinity of the samples, a microwave treatment was added to the synthesis procedure at selected processing steps. XRD analysis confirms that it is indeed possible to increase the crystalline anatase fraction present. Furthermore, it seems that this increased crystallinity does not substantially affect the specific surface area of the samples, but it enhances the surface photovoltage.

The photocatalytic activity of the samples was tested in both aqueous and gaseous media. Generally, it can be stated that the microwave treatment led to an increase in activity. In aqueous media, this was only the case for the sample with an increased specific surface area, but for the gaseous photocatalytic degradation all microwave-treated samples have an increased performance. For gaseous degradation reactions, the best material combines a high surface photovoltage with high photocatalytic activity both in absolute terms as well as per unit of area. Overall, a high specific surface area and good electrical properties are necessary to perform well in both gaseous and aqueous applications.

\section{Supplementary information}

The $[F(R) \cdot E]^{2}$ versus the energy (E) plot obtained from total reflectance UV-Vis spectroscopy that are used to calculate the band gap energies can be found in the supplementary information. TEM images of the samples are also depicted.

\section{Acknowledgements}

M. Meire and S. W. Verbruggen acknowledge the FWO-Flanders (Fund for Scientific Research-Flanders) for financial support. We want to thank $\mathrm{T}$.
Planckaert for the $\mathrm{N}_{2}$ sorption measurements, J. Watte for the XRD measurements, and professor K. De Buysser for the quantitative Rietveld refinements.

\section{Compliance with ethical standards}

Conflicts of interest The authors declares that there is no conflict of interest.

Electronic supplementary material: The online version of this article (doi:10.1007/s10853-016-0215y) contains supplementary material, which is available to authorized users.

\section{References}

[1] Carp O, Huisman CL, Reller A (2004) Photoinduced Reactivity Of Titanium Dioxide. Prog Solid State Chem 32:33-177

[2] Varghese OK, Gong DW, Paulose M, Ong KG, Grimes CA (2003) Hydrogen sensing using titania nanotubes. Sens Actuators B 93:338-344

[3] Grzybowska B, Sloczyski J, Grabowski R, Samson K, Gressel I, Wcislo K, Gengembre L, Barbaux Y (2002) Effect of doping of $\mathrm{TiO}_{2}$ support with altervalent ions on physicochemical and catalytic properties in oxidative dehydrogenation of propane of vanadia-titania catalysts. Appl Catal A 230:1-10

[4] Gaya UI, Abdullah AH (2008) Heterogeneous photocatalytic degradation of organic contaminants over titanium dioxide: a review of fundamentals, progress and problems. J Photochem Photobiol C 9:1-12

[5] Arin M, Lommens P, Avci N, Hopkins SC, De Buysser K, Arabatzis IM, Fasaki I, Poelman D, Van Driessche I (2011) Inkjet printing of photocatalytically active $\mathrm{TiO}_{2}$ thin films from water based precursor solutions. J Eur Ceram Soc 31:1067-1074

[6] Christensen PA, Curtis TP, Egerton TA, Kosa SAM, Tinlin JR (2003) Photoelectrocatalytic and photocatalytic disinfection of E. coli suspensions by titanium dioxide. Appl Catal B 41:371-386

[7] Fujishima A, Honda K (1972) Electrochemical Photolysis of Water at a Semiconductor Electrode. Nature 238:37-38

[8] Zhan E, Li Y, Liu J, Huang X, Shen W (2009) A VOx/Meso$\mathrm{TiO}_{2}$ catalyst for methanol oxidation to dimethoxymethane. Catal Commun 10:2051-2055

[9] Wang H, Miao JJ, Zhu JM, Ma HM, Zhu JJ, Chen HY (2004) Mesoporous spherical aggregates of anatase nanocrystals with wormhole-like framework structures: their
479

480

481

482

483

484

485

486

487

488

489

490

491

492

493

494

495

496

497

498

499

$\begin{array}{lll}\text { Journal : 10853 - Large 10853 } & \text { Dispatch : 14-7-2016 } & \text { Pages : } 8 \\ \text { Article No. : } \mathbf{2 1 5} & \square \text { LE } & \square \text { TYPESET } \\ \text { MS Code : JMSC-D-16-02783 } & \checkmark \text { CP } & \checkmark \text { DISK }\end{array}$


chemical fabrication, characterization, and photocatalytic performance. Langmuir 20:11738-11747

[10] Perathoner S, Lanzafame P, Passalacqua R, Centi G, Schlogl $\mathrm{R}$, Su DS (2006) Use of mesoporous SBA-15 for nanostructuring titania for photocatalytic applications. Micropor Mesopor Mater 90:347-361

[11] Zhang Z, Zuo F, Feng P (2010) Hard template synthesis of crystalline mesoporous anatase $\mathrm{TiO}_{2}$ for photocatalytic hydrogen evolution. J Mater Chem 20:2206-2212. doi:10. 1039/B921157H

[12] Kim DS, Kwak S-Y (2007) The hydrothermal synthesis of mesoporous $\mathrm{TiO}_{2}$ with high crystallinity, thermal stability, large surface area, and enhanced photocatalytic activity. Appl Catal A 323:110-118

[13] Dong W, Sun Y, Lee CW, Hua W, Lu X, Shi Y, Zhang S, Chen J, Zhao D (2007) Controllable and repeatable synthesis of thermally stable anatase nanocrystal-silica composites with highly ordered hexagonal mesostructures. J Am Chem Soc 129:13894-13904

[14] Kim DS, Han SJ, Kwak S-Y (2007) Synthesis and photocatalytic activity of mesoporous $\mathrm{TiO}_{2}$ with the surface area, crystallite size, and pore size. J Colloid Interface Sci 316:85-91

[15] Yu JC, Wang XC, Fu XZ (2004) Pore-wall chemistry and photocatalytic activity of mesoporous titania molecular sieve films. Chem Mater 16:1523-1530

[16] Choi SY, Mamak M, Coombs N, Chopra N, Ozin GA (2004) Thermally stable two-dimensional hexagonal mesoporous nanocrystalline anatase, $\mathrm{Meso}-\mathrm{Nc}-\mathrm{TiO}_{2}$ : bulk and crack-free thin film morphologies. Adv Funct Mater 14:335-344

[17] Ismail AA, Bahnemann DW, Robben L, Yarovyi V, Wark M (2010) Palladium doped porous titania photocatalysts: impact of mesoporous order and crystallinity. Chem Mater 22:108-116

[18] Primo A, Corma A, Garcia H (2011) Titania supported gold nanoparticles as photocatalyst. Phys Chem Chem Phys 13:886-910

[19] Baghbanzadeh M, Carbone L, Cozzoli PD, Kappe CO (2011) Microwave-assisted synthesis of colloidal inorganic nanocrystals. Angew Chem Int Ed 50:11312-11359

[20] Dufour F, Cassaignon S, Durupthy O, Colbeau-Justin C (2016) C Chaneac (2012) Do $\mathrm{TiO}_{2}$ Nanoparticles Really Taste Better When Cooked in a Microwave Oven? Eur J Inorg Chem 16:2707-2715

[21] Arin M, Lommens P, Hopkins SC, Pollefeyt G, Van der Eycken J, Ricart S, Granados X, Glowacki BA, Van Driessche I (2012) Deposition of photocatalytically active $\mathrm{TiO}_{2}$ films by inkjet printing of $\mathrm{TiO}_{2}$ nanoparticle suspensions obtained from microwave-assisted hydrothermal synthesis. Nanotechnology 23:165603
[22] Arin M, Watte J, Pollefeyt G, De Buysser K, Van Driessche I, Lommens P (2013) Low temperature deposition of $\mathrm{TiO}_{2}$ layers from nanoparticle containing suspensions synthesized by microwave hydrothermal treatment. J Sol-Gel Sci Technol 66:100-111

[23] Periyat P, Leyland N, McCormack DE, Colreavy J, Corr D, Pillai SC (2010) Rapid microwave synthesis of mesoporous $\mathrm{TiO}_{2}$ for electrochromic displays. J Mater Chem 20:3650-3655. doi:10.1039/B924341K

[24] Jena A, Vinu R, Shivashankar SA, Madras G (2010) Microwave assisted synthesis of nanostructured titanium dioxide with high photocatalytic activity. Ind Eng Chem Res 49:9636-9643

[25] Suprabha T, Roy HG, Thomas J, Kumar KP, Mathew S (2009) Microwave-assisted synthesis of titania nanocubes, nanospheres and nanorods for photocatalytic dye degradation. Nanoscale Res Lett 4:144-152

[26] Meynen V, Cool P, Vansant EF (2009) Verified syntheses of mesoporous materials. Micropor Mesopor Mater 125: 170-223

[27] Tian BZ, Yang HF, Liu XY, Xie SH, Yu CZ, Fan J, Tu B, Zhao DY (2002) Fast Preparation Of Highly Ordered Nonsiliceous Mesoporous Materials Via Mixed Inorganic Precursors. Chem Commun 17:1824-1825

[28] Beyers E, Cool P, Vansant EF (2007) Stabilisation of mesoporous $\mathrm{TiO}_{2}$ by different bases influencing the photocatalytic activity. Micropor Mesopor Mater 99:112-117

[29] Bish DL, Howard SA (1988) Quantitative phase analysis using the rietveld method. J Appl Crystallogr 21:86-91

[30] AA Coelho (2007) Topas Academic version 4.1

[31] Verbruggen SW, Dirckx JJJ, Martens JA, Lenaerts S (2013) Surface photovoltage measurements: a quick assessment of the photocatalytic activity? Catal Today 209:215-220

[32] Deng S, Verbruggen SW, He Z, Cott DJ, Vereecken PM, Martens JA, Bals S, Lenaerts S, Detavernier C (2014) Atomic layer deposition-based synthesis of photoactive $\mathrm{TiO}_{2}$ nanoparticle chains by using carbon nanotubes as sacrificial templates. Rsc Advances 4:11648-11653

[33] Verbruggen SW, Lenaerts S, Denys S (2015) Analytic versus CFD approach for kinetic modeling of gas phase photocatalysis. Chem Eng J 262:1-8

[34] Verbruggen SW, Deng S, Kurttepeli M, Cott DJ, Vereecken PM, Bals S, Martens JA, Detavernier C, Lenaerts S (2014) Photocatalytic acetaldehyde oxidation in air using spacious $\mathrm{TiO}_{2}$ films prepared by atomic layer deposition on supported carbonaceous sacrificial templates. Appl Catal B 160:204-210

[35] Brinker CJ, Scherer GW (1990) Sol-Gel science: the physics and chemistry of sol-gel processing. Acad Press, San Diego

\begin{tabular}{|l|lll|}
\hline Journal : 10853 - Large 10853 & Dispatch : 14-7-2016 & Pages : 8 \\
& Article No. : 215 & $\square$ LE & $\square$ TYPESET \\
MS Code : JMSC-D-16-02783 & $\sim$ CP & DISK \\
\hline
\end{tabular}

